\title{
In vitro Propagation of Eugenia uniflora $\mathrm{L}$.
}

\author{
Chiyomi UEMATSU*, Masanao TSUJIMOTO** and Masaaki SUGIMOTO*** \\ ${ }^{*}$ Botanical Gardens, Faculty of Science, Osaka City University, Kisaichi 2000, Katano, Osaka 576-0004, Japan \\ **Kansai Environmental Engineering Center CO., LTD., Nankou-Minami 7-3-8, Suminoe-ku, Osaka 559- \\ O032, Japan \\ *** The Kansai Electric Power CO., INC., Nakoji 3-11-20, Amagasaki, Hyogo 661-0974, Japan
}

Received 21 July 1998; accepted 25 November 1998

\begin{abstract}
Eugenia uniflora Linn. is one of the useful trees in tropical areas. In vitro propagation of E. uniflora was achieved by using newly elongating shoots as material. MS medium supplemented with $0.2 \mathrm{mg} l^{-1}$ of $6 \mathrm{BA}$ was suitable for shoot regeneration and proliferation. Shoot elongation, root induction and root elongation were successfully carried out by transplanting to $1 / 2$ MSHF medium. By this method more than fifty thousand regenerated plants can be obtained from one stem segment within one year. In vitro propagation of $E$. uniflora would be applicable not only for nursery production, but also for the conservation of genetic resources.
\end{abstract}

\begin{abstract}
Abbreviations
6BA, 6-benzyladenine; 4CPPU, $N$-(2-chloro-4-pyridyl)- $N^{\prime}$-phenylurea; 2,4-D, 2,4-dichlorophenoxyacetic acid; IBA, indolebutyric acid; NAA, naphthaleneacetic acid.
\end{abstract}

In vitro culture is an useful technique for conservation and propagation of important tree species in tropical areas. Eugenia uniflora Linn. (Myrtaceae), pitanga cherry, is one of the useful trees whose leaves have been used as folk medicine. It is considered to originate in south Brazil and Paraguay (Tropical Agriculture Recearch Center, Ministry of Agriculture, Forestry and Fisheries, Japan, 1974; Hirschmann,1988). The water decoction of $E$. uniflora leaves is widely used alone or mixed with decoction of other Myrtaceae leaves by Paraguayans. This water decoction is called "Ñangapiry" and recommended for use as a diuretic and antihypertensive medicine. It is known to lower blood pressure by reducing cholesterol and to reduce weight (Hirschmann et al., 1987; Ferro et al., 1988). E. uniflora is distributed widely over India, Sri Lanka, Philippines, southern part of China, North America and Europe after introduction by Portuguese. The fruit is about $2.5 \mathrm{~cm}$ in diameter and turns deep red after ripening. It is juicy, soft, sweet and sour, and has an aroma of strawberry (Tropical Agriculture Recearch Center, Ministry of Agriculture, Forestry and Fisheries, Japan, 1974). E. uniflora trees are cultivated for fruit production in Brazil, California, Florida and coastal land of the Mediterranean Sea.

Usually nursery stocks are propagated by seedlings, so that they show wide range of genetic diversity. If one tree which has good agronomic traits such as big or sweet fruits can be propagated rapidly via tissue culture, it would be useful for nursery productuion. Plant regeneration from immature adventitious embryos was reported in E. jambos and E. malaccensis (Litz, 1984). Shoot and root induction was observed in E. grandis using nodal segments and shoot tips as material (Sen et al., 1978). But there are no reports of tissue culture system about E. uniflora. In this study we report the tissue culture condition for rapid propagation of E. uniflora.

Newly elongating shoots were collected from $E$. uniflora plants maintained in a green house of the Botanical Gardens of Osaka City University. They were washed in the neutral detergent solution and rinsed under the tap water throughly. Then they were immersed in $70 \%$ ethanol for $5 \mathrm{~min}$ and treated with $0.3 \%$ sodium hypochlorite solution for $10 \mathrm{~min}$, followed by rinsing with sterilized water two times. After surface sterilization, 2 to $3 \mathrm{~mm}$ shoot segments having apical or axillary buds were used as explants.

Murashige and Skoog's medium (Murashige and Skoog, 1962) was used as a basal medium. Several growth regulators were supplemented to media to examine their effects on callus induction and organ regeneration. Media were solidified with $0.2 \%$ Gelrite and cultures were kept at $25^{\circ} \mathrm{C}$. During the first generation of culture, inocula were kept under continuous dark condition in order to prevent browning. After subculture they were moved to the condi- 

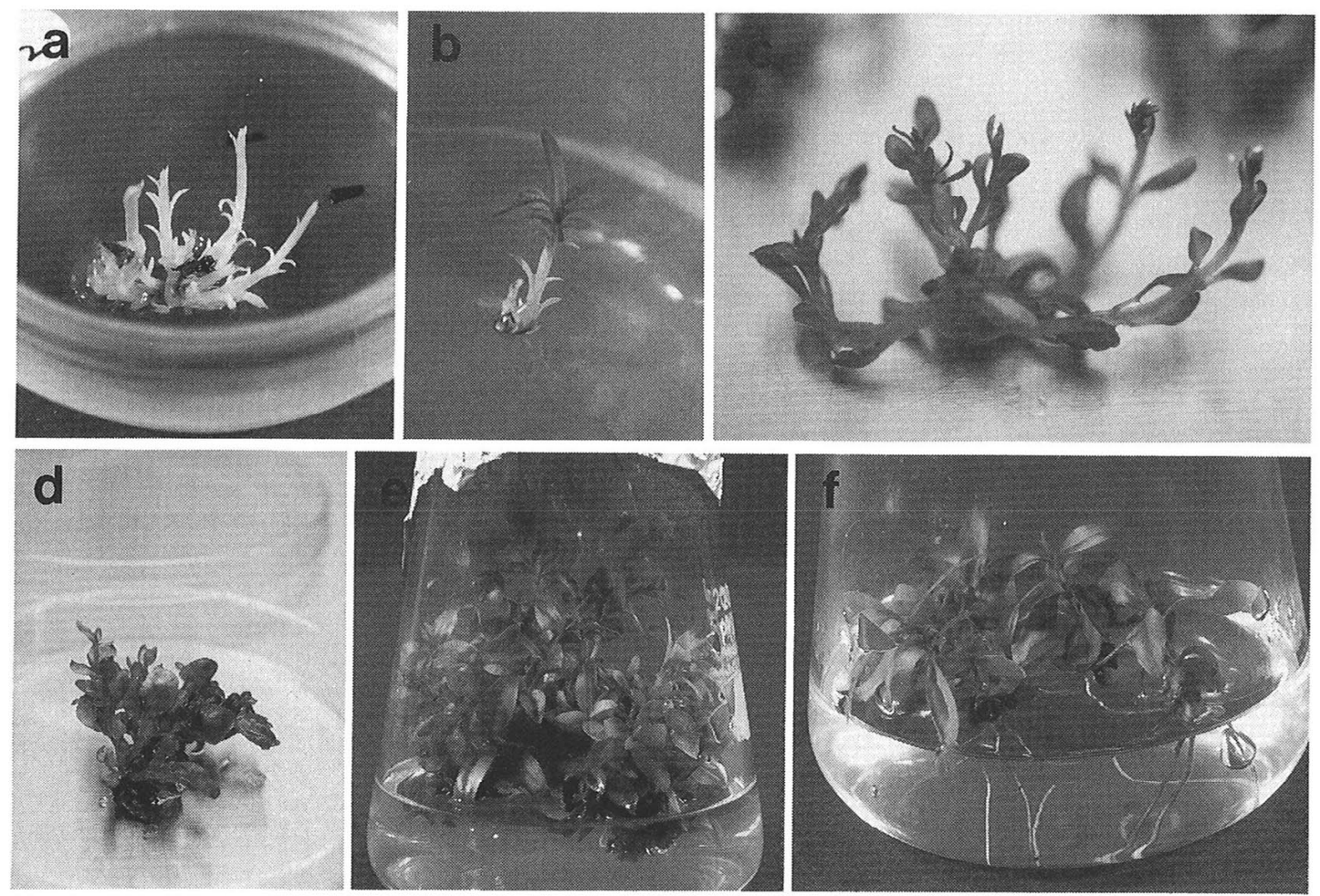

Fig. 1 Regeneration of E. uniflora plantlets via tissue culture.

a: Regeneration of etiolated shoots on MS+6BA medium after 20 weeks of culture under the continuous dark condition.

b: Shoot greening was observed after the transfer to 1/2MSHF medium under the $14 \mathrm{hr}$ light condition.

c: Shoot proliferation after 10 weeks of culture on MS+6BA medium.

d: Vitrified shoots observed on the MS+6BA medium.

e: Vigorously growing shoots at high increasing rate.

f: Rooting was observed when shoots were transferred from MS+6BA medium to $1 / 2 \mathrm{MSHF}$ medium.

Table 1. Effect of cytokinin and explant type on the shoot proliferation rate. ${ }^{\mathrm{a}}$

\begin{tabular}{ccc}
\hline \multirow{2}{*}{ Medium } & \multicolumn{2}{c}{ Type of explant } \\
\cline { 2 - 3 } & Normal shoot & Vitrified shoot \\
\hline 1/2MSHF & 3.5 & 10.3 \\
MS+4CPPU & 4.1 & $7.0^{\mathrm{b}}$ \\
MS+6BA & $15.5^{* 1}$ & $16.5^{* 2, \mathrm{~b}}$ \\
MS+Kinetin & 4.5 & $7.7^{\mathrm{b}}$ \\
MS+Zeatin & 4.3 & $5.7^{\mathrm{b}}$ \\
\hline
\end{tabular}

*1 Significant at 5\% level.

*2 Significant at $5 \%$ level except for $1 / 2 \mathrm{MSHF}$.

a Proliferation rate=Total number of shoots after 5 weeks culture / Number of transplanted shoots.

b Shoot vitrification was observed.

tion of $14 \mathrm{hr}$ photoperiod at $93 \mu \mathrm{mol} \mathrm{s}{ }^{-1} \mathrm{~m}^{-2}$ by fluorescent tubes (FL20S N-EDL; Mitsubishi/Osram, Yokohama).

In order to obtain callus or shoot regeneration, 2,4$\mathrm{D}$ and/or 6BA were added to the basal medium at the concentration of 0 to $10.0 \mathrm{mg} l^{-1}$. Twenty weeks after plating, five stem segments out of 48 regenerated shoots. Four of them were observed on media

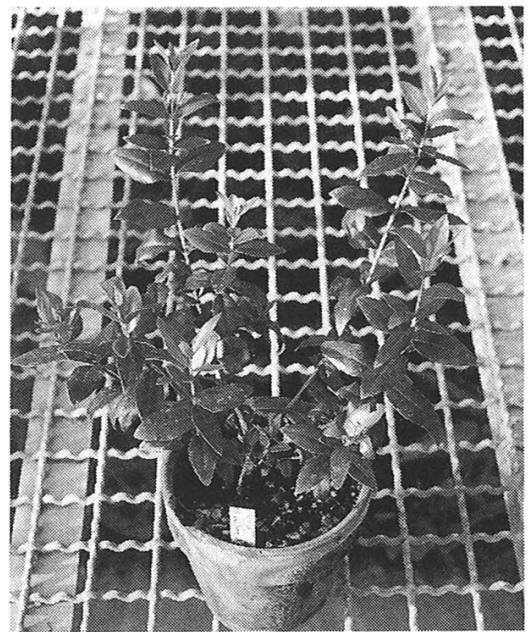

Fig. 2 A regenerated plant grown in a greenhouse.

containing 0.2 or $2.0 \mathrm{mg} l^{-1} 6 \mathrm{BA}$. One segment, cultured on medium supplemented with $0.2 \mathrm{mg} l^{-1}$ of $6 \mathrm{BA}$, regenerated more than six etiolated shoots (Fig. 1-a).

Regenerated shoots were divided into individual shoots and subcultured on half-strength MS medium without growth regulators (1/2MSHF medium) or the MS medium containing $0.2 \mathrm{mg} l^{-1} 6 \mathrm{BA}$. They were 
Table 2. Root induction and elongation after four weeks of culture on the rooting medium.

\begin{tabular}{|c|c|c|c|c|c|c|}
\hline \multirow{3}{*}{ Rooting medium } & \multicolumn{6}{|c|}{ Previous medium } \\
\hline & \multicolumn{3}{|c|}{$1 / 2 \mathrm{MSHF}$} & \multicolumn{3}{|c|}{$\mathrm{MS}+6 \mathrm{BA}$} \\
\hline & $\begin{array}{l}\text { Rooting fre- } \\
\text { quency }(\%)^{\mathrm{a}}\end{array}$ & No. root/shoot & $\begin{array}{l}\text { Mean length } \\
(\mathrm{cm})\end{array}$ & $\begin{array}{l}\text { Rooting fre- } \\
\text { quency }(\%)^{a}\end{array}$ & No. root/shoot & $\begin{array}{c}\text { Mean length } \\
(\mathrm{cm})\end{array}$ \\
\hline $1 / 2 \mathrm{MSHF}$ & 25.0 & 0.5 & 3.6 & 62.5 & 1.6 & 2.5 \\
\hline $1 / 2 \mathrm{MS}+\mathrm{IBA}_{\left(1.0 \mathrm{mg} l^{-1}\right)}$ & 85.7 & 3.6 & 0.4 & 57.1 & 2.4 & 0.4 \\
\hline $1 / 2 \mathrm{MS}+\underset{\left(0.1 \mathrm{mg} l^{-1}\right)}{\mathrm{NAA}}$ & 71.4 & 2.7 & 0.3 & 71.4 & 1.4 & 0.3 \\
\hline
\end{tabular}

a Rooting frequency $=($ Number of shoots with root/Number of shoot transplanted $) \times 100$

kept under the condition of $14 \mathrm{hr}$ light/10 hr dark. Within a few weeks the shoots turned green. Ten weeks after subculture shoots elongated on the $1 /$ 2MSHF medium, but there was no proliferation of shoot number (Fig. 1-b). On the other hand, in the case of the MS+6BA medium, all explants increased shoot number because of secondary shoot formation (Fig. 1-c). Ten weeks after subculture, total shoot number increased more than eightfold. The proliferated shoots were separated into individuals and subcultured on $1 / 2 \mathrm{MSHF}$ or MS+6BA media for further investigation to establish the suitable conditions for shoot elongation, root induction, and whole plant regeneration.

Vitrified shoot formation was often observed (Fig. 1-d). In order to clarify the effect of cytokinin or type of explant on the shoot proliferation rate, regenerated shoots were subcultured on media containing $6 \mathrm{BA}, 4 \mathrm{CPPU}$, kinetin, zeatin or no plant growth regulators. After five weeks of culture, vitrified shoots gave higher proliferation rates compared with normal shoots on all media examined (Table 1). Both normal shoots and vitrified shoots showed the highest shoot proliferation rate on medium containing 6BA (Fig. 1-e). When vitrified shoots were subcultured on 1/2MSHF medium, newly appearing shoots were not vitrified. But the proliferation rate was 10.3 which was higher than those obtained under other conditions except for the medium containing 6BA. Rooting was observed from 45 to $50 \%$ of the normal shoots subcultured to $1 /$ 2MSHF medium (Fig. 1-f).

In order to establish the rooting condition with $1 /$ 2MS medium as a basal medium, the effect of IBA and NAA was examined (Table 2). Proliferated shoots were dissected into individual shoots. Only shoots longer than $1.6 \mathrm{~cm}$ were transferred to the rooting medium. After four weeks of culture on the rooting medium, frequency of the rooting individuals per total shoots tranferred, number of roots per one shoot and mean length of all roots were examined. Media including IBA or NAA gave relatively higher rooting frequency than that without growth regulators. The number of roots per shoot varied among media. However these roots were very short, only 3 to $4 \mathrm{~mm}$, and thick, appearing different from the normal root. On the other hand, in spite of the low rooting frequency, roots elongated longer on $1 / 2 \mathrm{MSHF}$ medium than on medium containing IBA or NAA which showed whity and normal.

Rooted plantlets were transferred to pots filled with sterilized vermiculite and covered with glass beaker in order to keep the humidity high. These plants were kept in the incubater maintained at $25^{\circ} \mathrm{C}, 14 \mathrm{hr}$ light/10 hr dark condition. Two months later aclimatized plants were transferred to a greenhouse, and they grew vigorously (Fig. 2).

This study indicated that MS medium supplemented with $0.2 \mathrm{mg} l^{-1}$ of $6 \mathrm{BA}$ was suitable for shoot regeneration and proliferation of E. uniflora. Shoot elongation, root induction and root elongation were successfully achieved by transplanting to $1 / 2$ MSHF medium. By this method, we can obtain more than fifty thousand regenerated plants from one stem segment within one year. This is the first report on in vitro propagation of E. uniflora which would be applicable not only for the comercial production of leaves and fruits, but also for the conservation of genetic resources.

\section{Acknowledgements}

We thank Dr. Toshimitsu Hayashi, Toyama Medical and Pharmaceutical University, for providing for us information concerning the E. uniflora as Paraguayan folk medicine. This work was financially supported in part by The Kansai Electric Power CO. INC..

\section{References}

Ferro, E., Schinini, A., Maldonado, M., Rosner, J., Hirschmann, G. S., 1988. Eugenia uniflora leaf extract and lipid metabolism in Cebus apella monkeys. J. Ethnopharmacol., 24: 321-325.

Hirschmann, G. S., 1988. Ethnobotanical observations on paraguayan Myrtaceae. I. J. Ethnopharmacol., 22: 73-79. 
Hirschmann, G. S., Theoduloz, C., Franco, L., Ferro, B. E., De Arias, A. R., 1987. Preliminary pharmacological studies on Eugenia uniflora leaves : xanthine oxidase inhibitory activity. J. Ethnopharmacol., 21: 183-186.

Litz, R. E., 1984. In vitro responses of adventitious embryos of two polyembryonic Eugenia species. HortScience, 19: 720-722.

Murashige, T., Skoog, F., 1962. A revised medium for rapid growth and bioassays with tobaacco tis- sue cultures. Physiol. Plant., 15: 473-497.

Sen, C. Y., Hoong, H. S., Lay, F. F. M., 1978. Preliminary investigations on the propagation of Eugenia grandis through tissue culture. Gradens' Bulletin, Singapore, 31: 253-254.

Tropical Agriculture Research Center, Ministry of Agriculture, Forestry and Fisheries, Japan, 1974. Fruits in South East Asia (J) (Tounan Ajia No Kaju), 400-405. Association of Agriculture and Forestry Statistics, Tokyo. 